
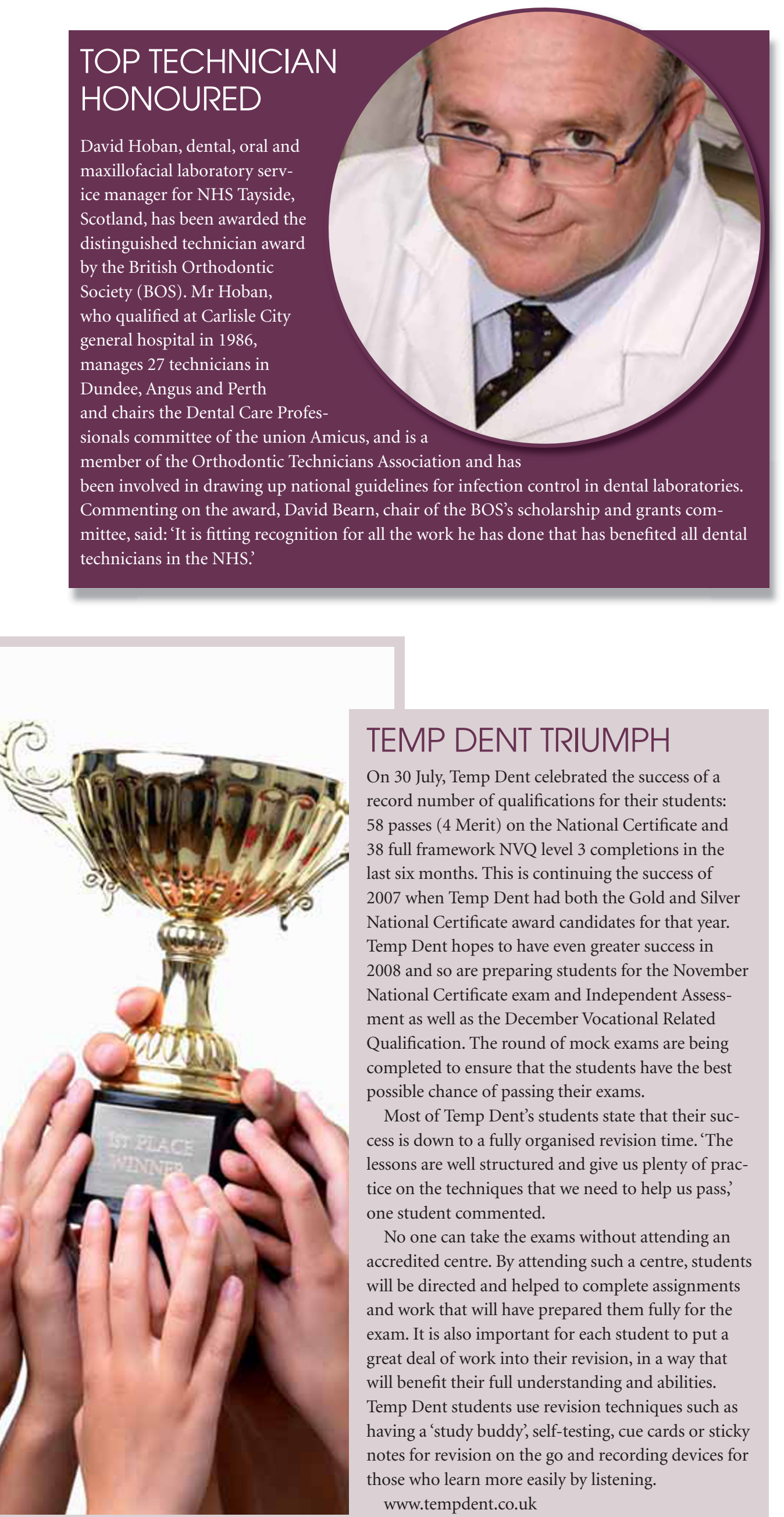

\title{
TEMP DENT TRIUMPH
}

On 30 July, Temp Dent celebrated the success of a record number of qualifications for their students: 58 passes (4 Merit) on the National Certificate and 38 full framework NVQ level 3 completions in the last six months. This is continuing the success of 2007 when Temp Dent had both the Gold and Silver National Certificate award candidates for that year. Temp Dent hopes to have even greater success in 2008 and so are preparing students for the November National Certificate exam and Independent Assessment as well as the December Vocational Related Qualification. The round of mock exams are being completed to ensure that the students have the best possible chance of passing their exams.

Most of Temp Dent's students state that their success is down to a fully organised revision time. 'The lessons are well structured and give us plenty of practice on the techniques that we need to help us pass,' one student commented.

No one can take the exams without attending an accredited centre. By attending such a centre, students will be directed and helped to complete assignments and work that will have prepared them fully for the exam. It is also important for each student to put a great deal of work into their revision, in a way that will benefit their full understanding and abilities. Temp Dent students use revision techniques such as having a 'study buddy', self-testing, cue cards or sticky notes for revision on the go and recording devices for those who learn more easily by listening.

www.tempdent.co.uk 